\title{
THE HUMAN PACEMAKER AND ITS PATHOLOGY*
}

\author{
BY \\ REGINALD E. B. HUDSON \\ From the National Heart Hospital and the Institute of Cardiology \\ Received July 24, 1959
}

There is a remarkable remnant of primitive fibres persisting at the sino-auricular junction in all mammalian hearts. These fibres are in close connection with the vagus and sympathetic nerves, and have a special arterial supply; in them the dominating rhythm of the heart is believed to normally arise.

Keith and Flack, 1907.

One summer afternoon in 1906, Martin Flack, a young medical student at the London Hospital Medical College, called on his friends Dr. and Mrs. Arthur Keith at their farmhouse, Mann's Place, near the Kentish village at Bredgar. The acquaintance, which developed into a life-long friendship, started when the roundsman of Mr. Flack, a butcher and grocer in nearby Borden, told the Keiths that Martin (Mr. Flack's son) was going to be a doctor, and had just completed the basic examinations at Oxford. Dr. Keith, who was lecturer in anatomy at the London Hospital, lost no time in persuading him to continue his medical studies at the London.

During the long vacation of 1906, Flack helped Dr. Keith to turn his study at the farmhouse into a laboratory. They had a vast store of human hearts, and were trapping moles, rats, mice, and hedgehogs, with the intention of verifying and extending Tawara's momentous discoveries in connection with the atrio-ventricular node (from which the bundle of His arises). On this particular hot summer afternoon, Dr. Keith and his wife wanted to go for a bicycle ride so they invited young Flack to busy himself cutting serial sections from a paraffin block in which was embedded the heart of a mole.

When they returned, they found Flack in a state of great excitement. He bade Dr. Keith look through the microscope at a strange structure he had found at the junction of the superior vena cava with the right auricle. It was muscular, but quite different from the musculature round about, and it reminded Keith of the body (node of Tawara) that he had seen in the MacKenzie hearts.

With great enthusiasm, Keith and Flack set to work and found this structure at the same site in all the mammalian hearts at their disposal, and thus it became known as the sino-auricular (now sinu-atrial) node of Keith and Flack; it resembled the atrio-ventricular node of Tawara and hence they inferred it to be the site at which the cardiac rhythm was normally initiated (Keith, 1942 and 1948.) In 1910, Thomas Lewis and the Oppenheimers were able to call the node of Keith and Flack the pacemaker of the heart. This was as a result of their brilliant work on the origin of the heart-beat in the dog. They found that the point of primary negativity, which is considered to be the site of primary activity, was located at a point on the sino-auricular junction corresponding with the cephalic extremity of Keith and Flack's node. This point was marked at the animal experiments and subsequently examined histologically by the Oppenheimers (1912) at the Royal College of Surgeons - with permission of Arthur Keith, who had become Professor and Curator of the Museum.

Even with the lapse of half a century, one is humbled and fascinated by the work and writings of these giants of cardiological research, exploring completely unknown fields with resources so much

* St. Cyres Lecture, delivered on June 2, 1959, at The Royal Society of Medicine, under the auspices of The National Heart Hospital. 
less than we have today. Some idea of the enormous.interest stimulated by their classical and still undisputed discoveries is found in the long review by Eyster and Meek in 1921 which lists 145 references to work on the conducting system of the heart. Their paper, incidentally, casts some doubt (based on ablative experiments), on the importance of the sino-auricular node as the heart pacemaker. As recently as 1954, Puech et al. (1954), however, published an account of the spread of atrial activation in the dog's heart: using modern unipolar and bipolar electrodes, they confirmed its origin from the node area.

Apart from Eyster and Meek, the only other discordant note was struck by the Glomsets in 1940: they made an extraordinary and misleading statement about the node, which is worth quoting if only to illustrate the confusion that has shrouded the pacemaker at times. They said that from a morphological study of the region of the node in human, equine, porcine, bovine, and ovine hearts, the node of Keith and Flack was " only a segment of a sheet of muscle which covers the first part of the vena cava superior, and spreads to the left to form the atrial myocardium."

Although individual workers may be quite sure of the exact location of the node and of its appearances, Taussig in 1931 illustrated the confusion in a drawing that located the node in different places according to various authorities. I believe that much confusion about the node still exists and, having regard for the great advances in cardiac surgery, thought it worthwhile to revive interest in the pacemaker, since this vital structure is of first importance to the cardiac surgeon and of great interest to the cardiologist.

The study was undertaken to verify the macroscopic and microscopic anatomy of the node, and to try and correlate its appearances with the heart rhythm that was present in life. During the past four years, I have examined the sinu-atrial node histologically in 65 formalin-fixed human hearts, including one fotal heart. All these hearts, excepting the fœtal, were abnormal in some respect.

It can be stated at once that the pacemaker is not immune from many of those processes that affect the rest of the heart; nor, indeed, would one expect it to be. Its identification is sometimes no easy matter, particularly when it is diseased; and this accounts for the difficulty in locating the node every time, and having found it, in saying if it looks normal or not. On this latter point, scrutiny of numerous sections from different hearts in sequence leaves no.doubt as to the variations in appearance in normal and in diseased nodes. At the same time, it is well realized that function cannot always be interpreted from histological appearances of a formalin-fixed, post-mortem specimen. Attempts at naked-eyed demonstration of the node by painstaking dissection under a lens have proved unrewarding. Histological methods are, however, far superior, and contrary to expectation do not really require more than a few blocks for routine study.

\section{The Normal Adult Node}

Fig. 1 illustrates the main features of an average normal human sinu-atrial node in the adult heart. If one examines the sinu-atrial junction (where the superior vena cava joins the right atrium) in the human heart, the atrium will be seen to climb forwards on the antero-lateral aspect of the vena cava to reach a summit, falling away again towards the medial side. I have found that this summit, marked $X$, is the landmark for the node. Sometimes it is bold, as in the photograph, at other times it is more blunted. It has been found easily in every heart so far examined, with only one exception that will be described later.

To secure histological examination, vertical strips are cut starting from the mouth of the superior vena cava with the heart held with its posterior surface towards one, as in the right-hand top photograph. These strips may be as numerous as desired; and extend backwards on each side as far as the pericardial reflections on to the left atrium and pulmonary veins. In Fig. 1 the required area is shown excised, stretched out, and marked into nine vertical strips. The small circular "ground plan" will be used in subsequent illustrations since this is our routine method of identifying the origin of any particular strip.

All the tissues examined were fixed in 10 per cent formol-saline. Although the node is often 
AN AVERAGE NORMAL S.A. NOdE

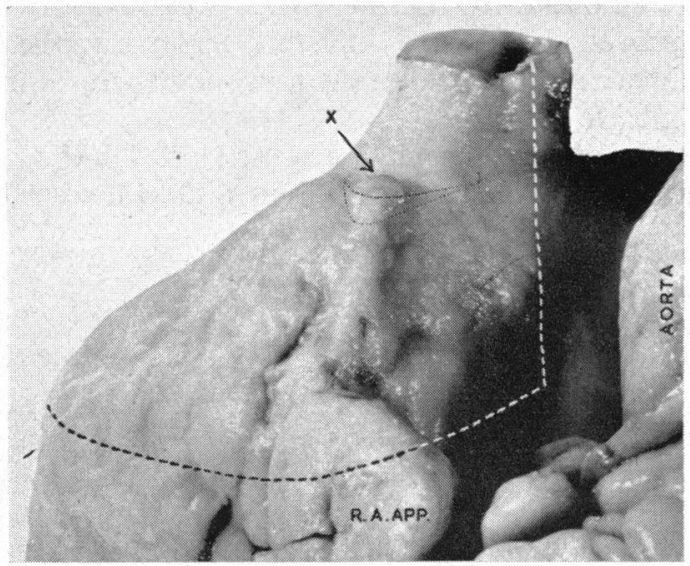

ANTERIOR VIEW OF SUPERIOR VENA CAVA TO SHOW

THE SUMMIT $X$ OF THE RIGHT ATRIUM AND ITS

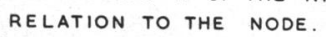

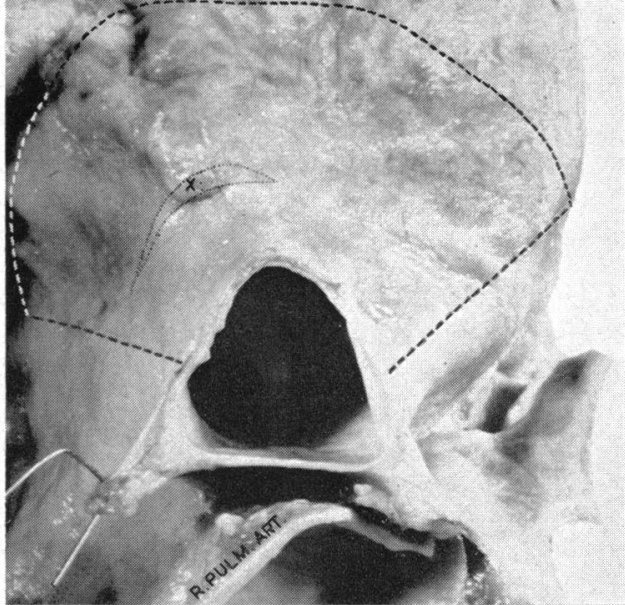

OVERHEAD VIEW.

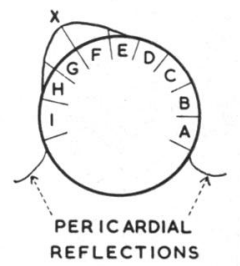

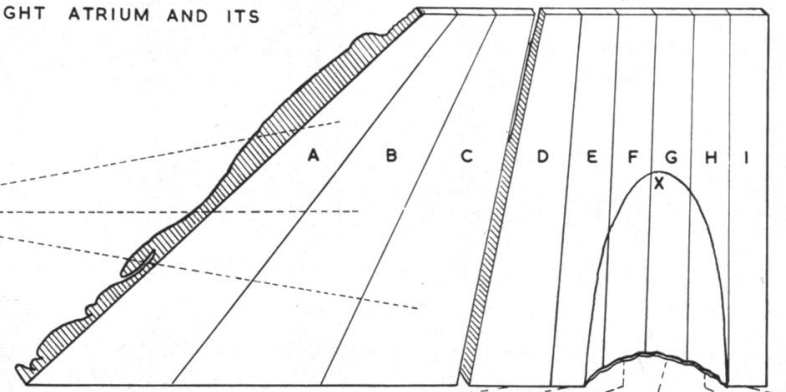
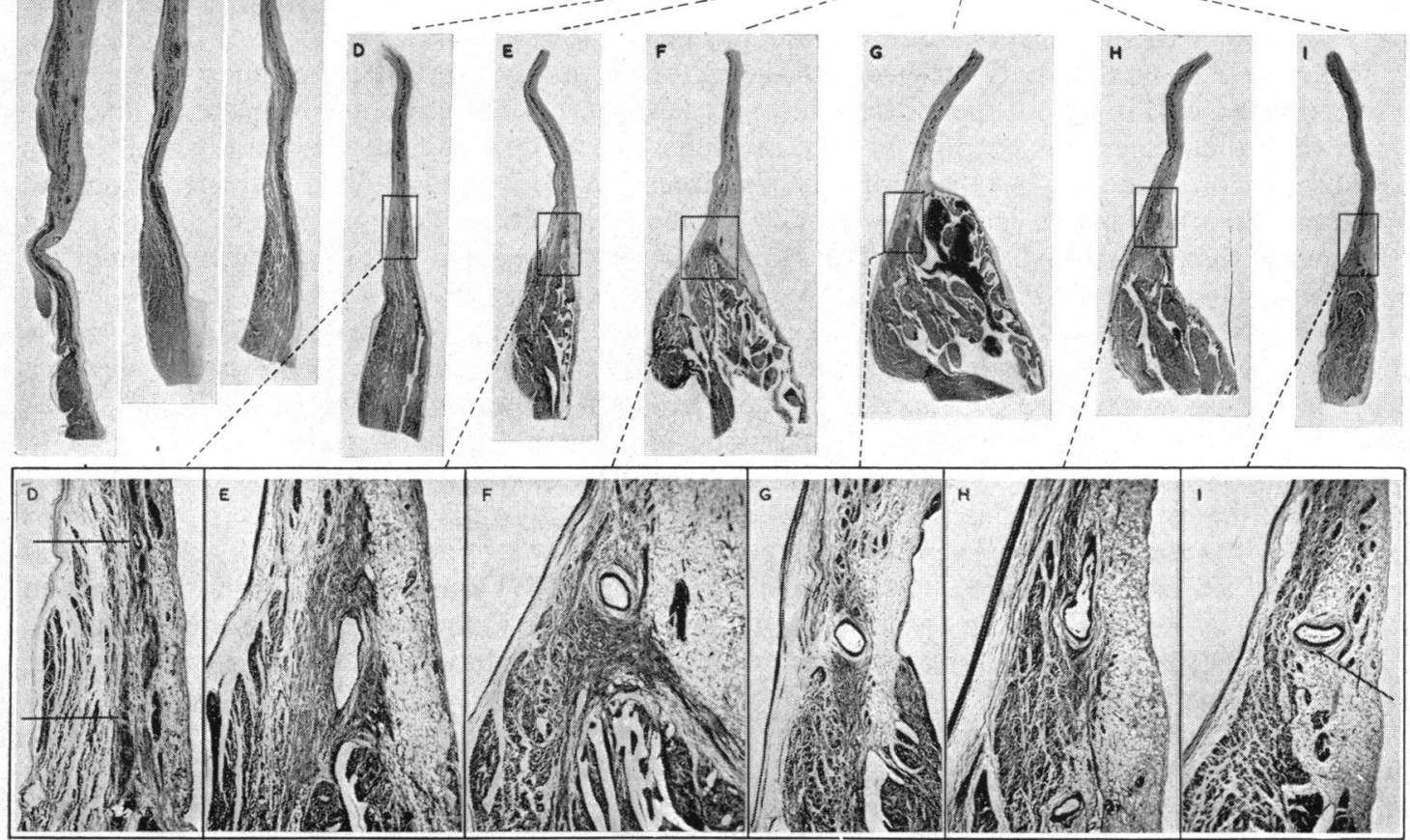

FIG. 1.-Anatomy and histology of sinu-atrial node. See text. 
quite distinct in hæmatoxylin-eosin preparations, the staining that has yielded the best results is Verhoeff-van Gieson. We have found this superior to all others for routine work. For low-power photographic demonstration as in Fig. 1, which has proved exceptionally difficult, we have applied the silver method of Holmes to sections 20 microns thick and this enables the nervous structures in and around the node to be examined, as well as the muscle striation.

In the row of nine whole-section photographs, the node is seen only in the medial six. In these, the node area outlined has been magnified in the bottom row of photomicrographs, D to I.

I-Node artery distinct. The arrow indicates a few node cells adjacent to the artery.

$\mathrm{H}-\mathrm{A}$ little nodal tissue mainly below the artery.

G-Node now elliptical, with the artery above its centre.

$F$ and $E-$ Main body of the node.

D-The artery has now divided into branches, two of which are indicated by arrows. Stretched out between the two arteries is a broken line of nodal tissue, hardly distinguishable in the picture from nearby atrial muscle.

The histological anatomy learned from the photographs has been transferred to the top photographs. In this heart, as in the majority of hearts examined (including the fortal heart), the main part of the node lies immediately beneath the epicardium, just below the summit X, more commonly towards its right side than its left. Occasionally, one finds the main part of the node more medially or laterally; in one heart (atrio-ventricularis communis) it was found adjacent to the right pulmonary veins. In any case, the atrial summit, $X$, provides a vital landmark and strips of tissue must always include it. The node usually lies immediately adjacent to the fatty epicardium, with no intervening atrial muscle. Occasionally, it reaches the endocardial surface also (a good example is seen in Fig. 12).

Histology of the Normal Node. The average normal adult node is a crescentic vascular neuromyocardial structure, quite distinctly marked off from the neighbouring tissues by being embedded in a variable amount of fibro-elastic tissue (Fig. 2A and B). At its largest part it is about three or four times the size of a pin's head. From this part, it tapers medially and laterally to a point. Occasionally it tapers and then re-expands before narrowing again. Quite often, one sees not one artery but two or more branches, and the node may be disposed around all or some of the branches.

The muscle is undoubtedly striated but this is often poorly marked by ordinary stains; the striations show well in silver preparations, however (Fig. 2D). The fibres are branching and interwoven so that some appear cut transversely and others at various angles. This is especially so in the substance of the node. At the periphery, the fibres run more vertically and they are longer and straighter, often forming an incomplete border to the node. The node muscle fibres are usually a little smaller than those of the right atrium (Fig. 2C). I have come to regard the appearance of the muscular component as the most helpful guide to the probable function of the node.

Nervous tissue is abundant in the node itself, and in the nearby epicardium there are always numerous parasympathetic ganglia and autonomic nerves to be found. Lewis stated that the nerves to the pacemaker are derived mainly from the right vagus and sympathetic, the left vagus and sympathetic serving the atrio-ventricular node of Tawara. It is interesting at this point to note that the pacemaker lies at the origin of the right horn of the sinus venosus (i.e. the superior vena cava); the atrio-ventricular node of Tawara lies near the origin of the left horn of the sinus venosus (i.e. the coronary sinus) so that, embryologically, the two nodes are symmetrically disposed as right- and left-sided structures. Stotler and McMahon (1947) found very extensive innervation of the node, as I have. The pioneer workers, Argaud in 1911, the Oppenheimers in 1912, and Meiklejohn in 1914 and, more recently, Blair and Davies in 1935, have all given descriptions of the nervous elements in the node.

The nerve bundles in the epicardium are often closely associated with muscle fibres (some obviously striated) as the node is approached. Fig. 3A shows a large nerve running into the lower left corner of the node and occasionally one may see several large nerve bundles cut across in the 



FIG. 2.-(A) A normal adult node. Verhoeff-van Gieson $\times 12$. (B) Area inside rectangle of (A). Node muscle paler than the wavy fibrous tissue. Scattered black elastic fibres. Node artery on top right. $\times 75 . \quad$ (C) Right atrial myocardium to show striations. Holmes' silver method. $\times 630$. (D) Nodal muscle to show striations - same section. The fibres are more interwoven and a little thinner. Holmes' silver method. $\times 630$.

substance of the node. Rarely, an isolated ganglion-cell can be found in the node, but there are no large ganglia.

The demonstration of nerve-endings in the node is difficult. All the tissues take the silver impregnation to some degree and the identification of fine nerve fibres is like looking for straw in a haystack. However, Fig. 3B shows a number of fine fibres, carrying prominent swellings and 
appearing to be mingled with adjacent muscle fibres. It is not possible to show in a single high power picture that these fibres seem to end on the surface of a muscle fibre, but Stotler and McMahon in 1947 stated that the terminal fibres are applied to the sarcolemma of every muscle fibre and that they remain epilemmal, i.e. on the surface.

The blood-supply to the node is variable. Keith and Flack said that the arteries are derived from the right and left coronary arteries to form an arterial circle. Lewis, in 1925, amplified this to say that the blood-supply is usually derived from the right coronary artery through a twig that passes backwards and upwards on the aortic surface of the right atrium. I have dissected out this artery several times; it often anastomoses with a similar branch derived from the left coronary artery.

I have found that the main part of the node may contain one large artery or two or more branches. In serial blocks, one main artery may be encountered either medially or laterally, indicating that the

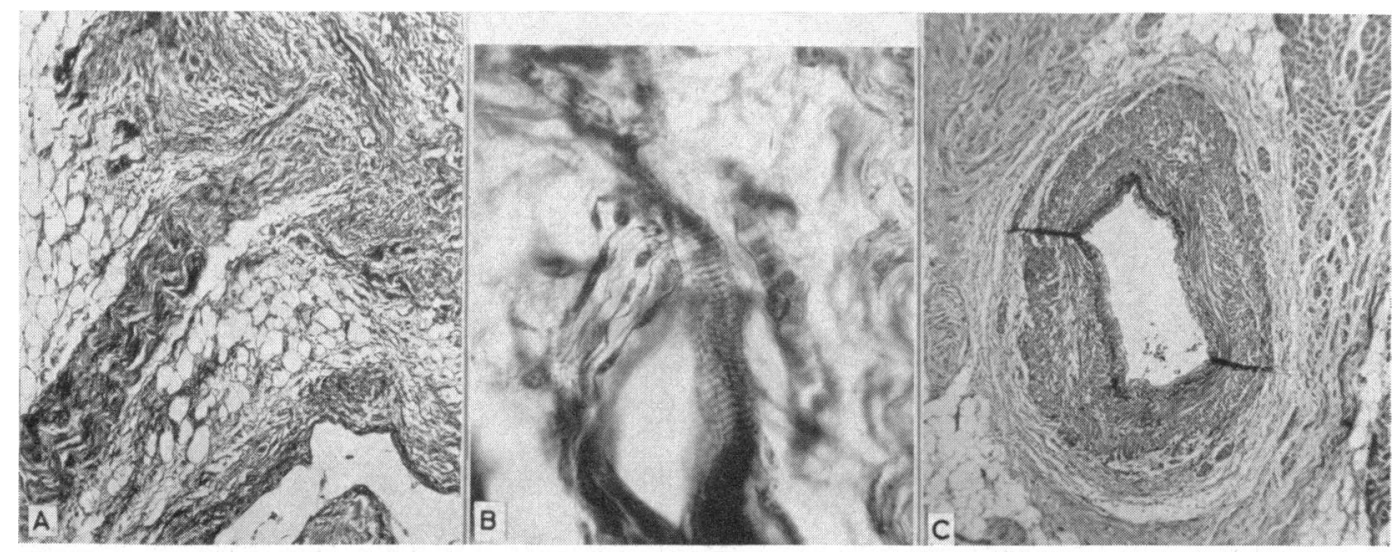

Fig. 3.- (A) Large dark-staining nerve-bundle runs from bottom left to the lower corner of the node at top right. Verhoeff-van Gieson. $\times 55$. (B) Nerve fibrils with fusiform swellings mingled with striated node muscle fibres. Just right of centre is a capillary and at the right edge is a large nerve bundle. Holmes' silver method. $\quad \times 495$. (C) Node artery with three layers in places. Verhoeff-van Gieson. $\times 35$.

main artery may enter the node either from the left or the right. Occasionally, there are multiple arteries throughout the length of the node. When there is more than one artery, nodal tissue may tend to be disposed around one of the branches only.

From the main arteries, there is a profuse blood supply to the node, which shows an abundance of arterioles and capillaries. An interesting feature of the nodal arteries is the arrangement of the muscle of the media. These fibres are commonly arranged in distinct layers, with an inner circular and an outer longitudinal coat or the reverse arrangement. In Fig. 3C, three layers can be distinguished in places.

Veins are inconspicuous in the node and so are lymphatics, although there are numerous lymphatic vessels in the adjacent epicardium. The supporting tissue of the node is mainly fibrous tissue, with some elastic fibres and a variable amount of fatty tissue. This makes the node a fairly compact body-rather more so, I think, than the node of Tawara. In spite of this, naked-eye demonstration is very difficult.

The fetal node differs somewhat from the adult node in being rather loosely knit and less clearly defined. In Fig. 4A, the node is indicated as a triangular mass just under the epicardium. The central artery can just be distinguished. The muscle fibres are not yet clearly striated (Fig. 4B); nor has the muscle of the adjacent right atrium (Fig. 4C) assumed the adult striation. In the nearby epicardium young autonomic structures can be found. Duckworth (1952) stated that connective tissue increases rapidly and muscle striations appear in the node at birth. 



FIG. 4.-Fœtal pacemaker. (A) General view. The node border is indicated by the arrows as roughly triangular. The node artery can just be seen in the centre of the node. Verhoeff-van Gieson. $\times 9$. (B) Detail of node, showing loose texture. The muscle fibres are finely granular but not yet striated. $\times 440$. (C) Right atrial myocardium, same section, to show striations - not yet of adult appearance. $\times 440$. (B) and (C) Holmes' silver method.

To complete this picture of a normal pacemaker, I want to dispel the idea that the sinu-atrial node is an isolated structure, with no visible connections with the rest of the heart. In Fig. 5A, stained with silver, extensions can be seen passing upwards towards the superior vena cava and downwards deep into the atrial myocardium. It is fairly common to find these extensions, and in them one may see muscle, sometimes distinctly striated, mingled with nerve fibres. One of these
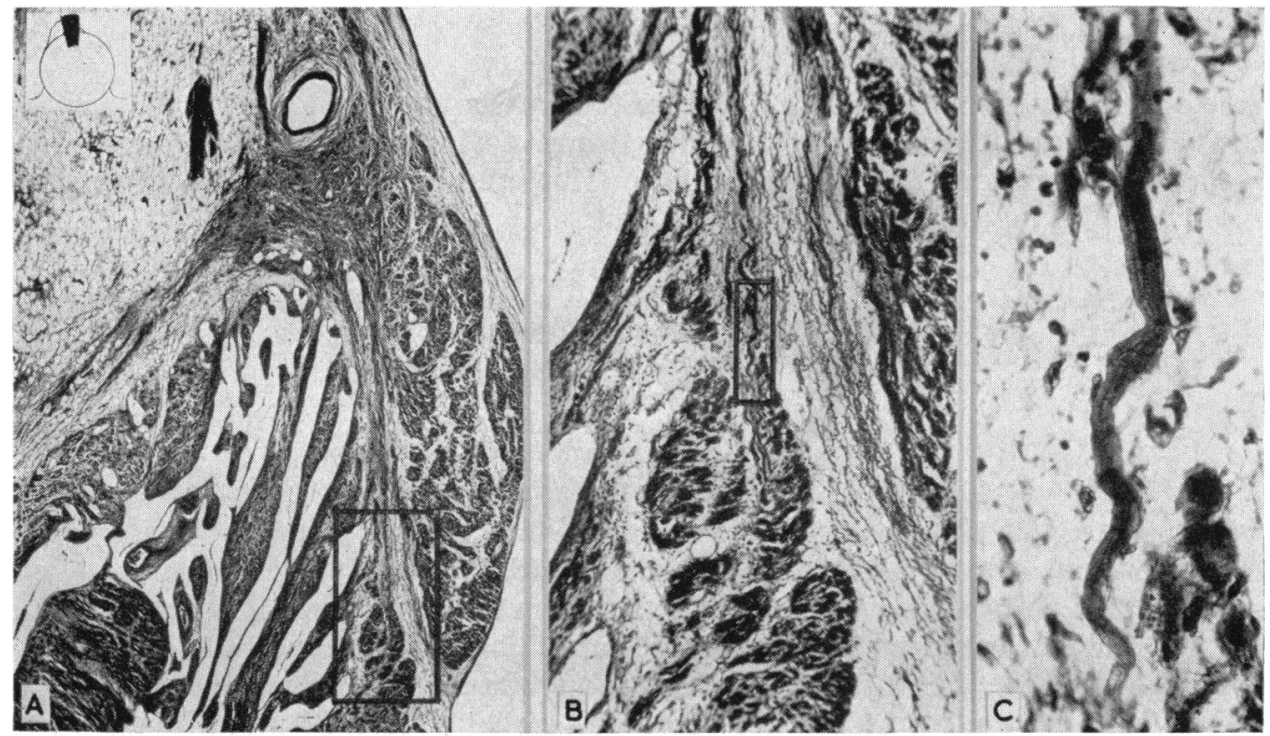

Fig. 5.-Node extensions. All stained with Holmes' silver method. (A) General view of node, showing extensions passing upwards around the artery towards the superior vena cava, and downwards deep into the right atrial myocardium. $\times 11$. (B) Enlarged view of the area inside the rectangle in $(\mathrm{A})$, showing an extension ending in the right atrial myocardium. $\times 40$. (C) Enlarged view of the single fibre inside the rectangle of (B) near the end of the extension, showing muscle striations. $\times 265$. 
extensions into the right atrium in Fig. 5A has been enlarged in Fig. 5B, and a single fibre from this enlarged in Fig. 5C to show that it is indeed striated muscle.

Taussig in 1931 reported that she found what she thought were Purkinje cells quite high up the superior vena cava. The criterion one must adopt in identifying outlying islets of node-like tissue is the demonstration of their direct connection with the main node. This can only be established by serial section, a method not feasible in the present study. Nevertheless, I have seen enough to convince me that the sinu-atrial node is indeed connected to the right atrium and sinus venosus.

\section{LESIONS OF THE NODE}

Sixty-five hearts were studied. All were abnormal, except the one fœtal heart. Although this series is fairly comprehensive, there is one important gap-namely, the heart of thyrotoxicosis, which I have not yet had the opportunity to study-it included examples of the following conditions:

Chronic rheumatic heart disease
Calcific aortic valve stenosis
Myocardial infarction
Cor pulmonale
Bacterial endocarditis
Systemic hypertension
Primary pulmonary hypertension
Polyarteritis nodosa
Aortitis
Dissecting aneurysm
Refsum's disease
Cardiopathy
Isolated arrhythmias-
Paroxysmal tachycardia
Atrial fibrillation

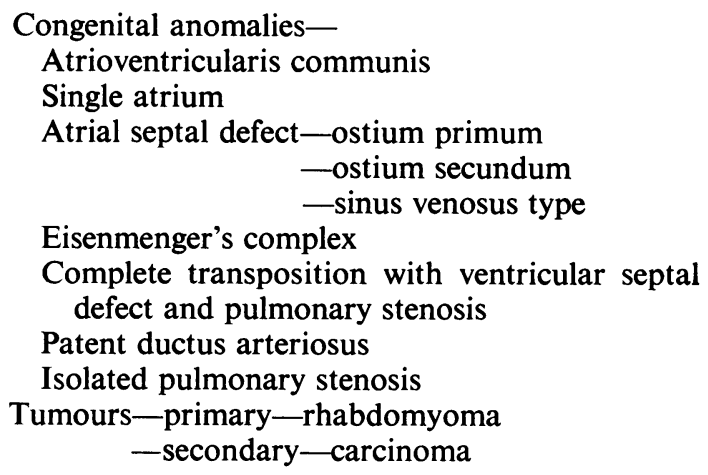

I made a "blind study" of the nodes of these 65 hearts and tried to assess any damage present. Then Dr. Leslie Davies looked up the case notes, some of which were, of course, several years old, and supplied details of the heart rhythm in life. This information was added to my histological findings. The following summariszes what I found.

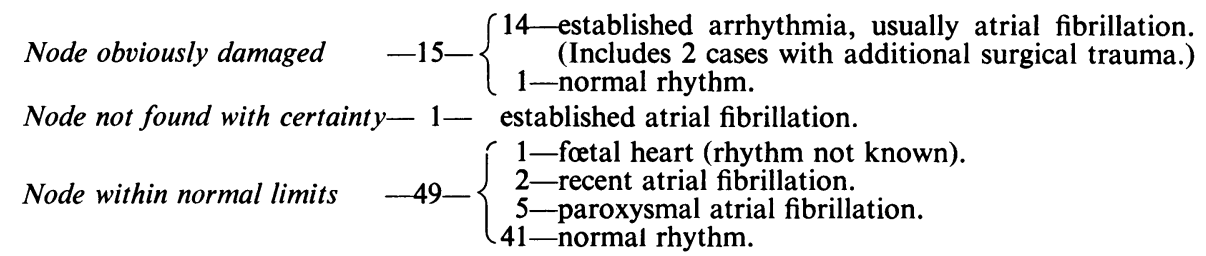

Interest has mainly centred on the hearts with obviously damaged nodes. These were found in chronic rheumatism, calcific aortic valve stenosis, cardiac infarction, cardiomyopathy, isolated pulmonary stenosis, and atrial septal defect (both ostium secundum and sinus venosus types).

In all these nodes, the constant lesion was the depletion and poor staining of nodal muscle with corresponding increase of fibrous, fibro-elastic, or fatty tissue. Sometimes the node was so badly damaged that only the arteries could be identified with certainty, or perhaps only one of the strips of tissue would show a little surviving node. The right atrium nearly always showed muscle damage and increase of interstitium in these cases, and it seems that the node and atrium were affected together. It is probable that in a damaged node, the nervous components will be involved also, since they are an integral part of node structure. The demonstration of such lesions is, however, beyond the scope of the present study. 


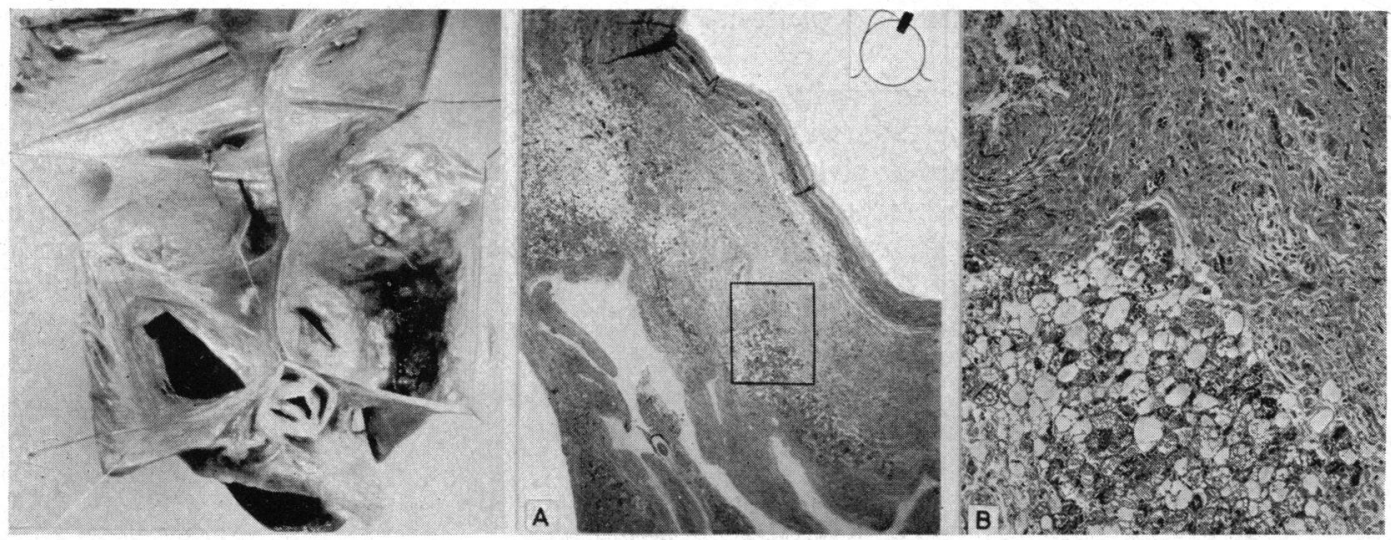

FIG. 6.-Gross node damage in chronic rheumatism with atrial fibrillation. Heart from a woman of 50, showing mitral stenosis, aortic stenosis, tricuspid regurgitation, and a very large right atrium. (A) General view of node, which is hard to distinguish. Right atrial myocardium severely damaged also. Verhoeff-van Gieson. $\quad \times 9$. (B) Area inside rectangle of (A). Artery at top left. Gross invasion of the node (to the right of the artery) by fibro-fatty tissue, with severe muscle depletion. Atrial myocardium below the node also severely damaged. $\times 54$.

Four examples of gross node lesions are illustrated in Fig. 6-9. The low-power pictures that follow carry a ground plan indicating the origin of the section illustrated. Fig. 6 shows the heart of a woman of 50 , with mitral and aortic valve stenosis, tricuspid regurgitation, and a very large right atrium: there had been established atrial fibrillation for 17 years. Fig. 6A is a general view of the node, which is hard to distinguish, even in the detail in $6 \mathrm{~B}$, from nearby damaged right atrium, although the artery is well seen. There is gross invasion of the node to the right of the artery by

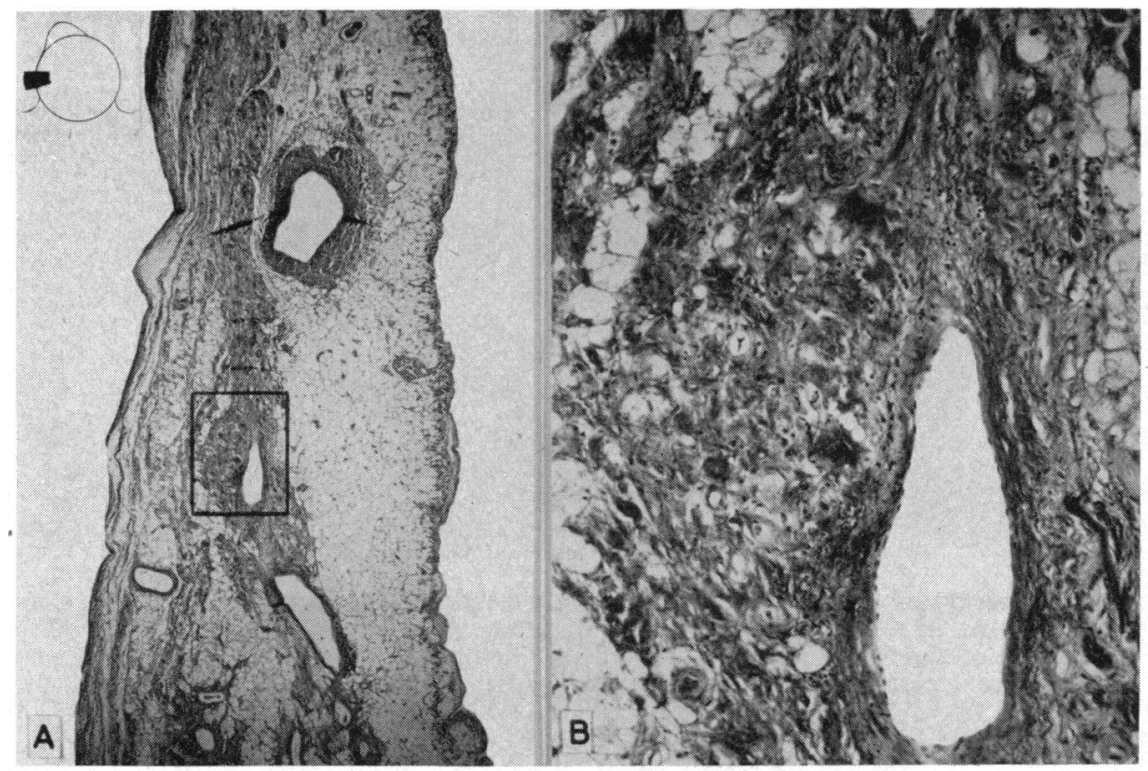

FIG. 7.-Severe node damage in cardiopathy. From the heart of a woman of 49 with established atrial fibrillation. (A) General view of the surviving nodal tissue, situated medially. Several arteries; with node mainly around the artery inside the rectangle. Verhoeff-van Gieson. $\quad \times 12$. (B) Detail of area inside rectangle of (A). Tissue mainly dark-staining fibrous tissue, with some fatty invasion. $\times 75$. 
fibro-fatty tissue and severe muscle depletion. The atrial myocardium below the artery is also severely damaged.

Fig. 7 illustrates the node from the heart of a woman of 49 with cardiopathy and established atrial fibrillation. The heart was enlarged generally, but the only naked-eye lesion was a small scar in the left ventricle. The low-power picture (Fig. 7A) shows the largest portion of node to be found in this specimen, and it will be seen from the ground plan that this section was taken from the medial side of the landmark. There are several arteries, most of the node being distributed around the artery inside the rectangle. Fig. 7B shows that this nodal tissue is largely dark-staining fibrous tissue, with some fatty invasion.

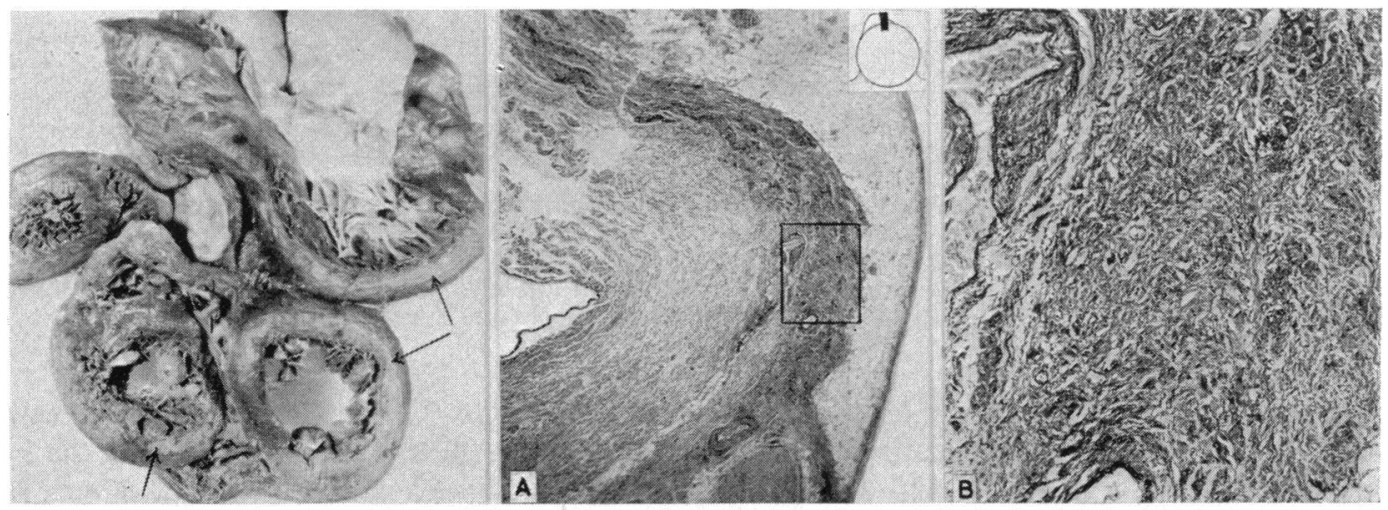

FIG. 8.-Elastosis of node in myocardial infarction. Woman of 68 with large recent posterior infarction indicated by the arrows, and a history of paroxysmal atrial fibrillation. (A) General view of node which is clearly defined as the dark central strip by the excess of elastic tissue. The main artery lies to the inner side of the node, with branches in the node and in its medial limb below. Verhoeff-van Gieson. $\times 9$. (B) Area inside rectangle of (A) to show the widespread distribution of the elastic tissue, with loss of nodal muscle. $\times 54$.
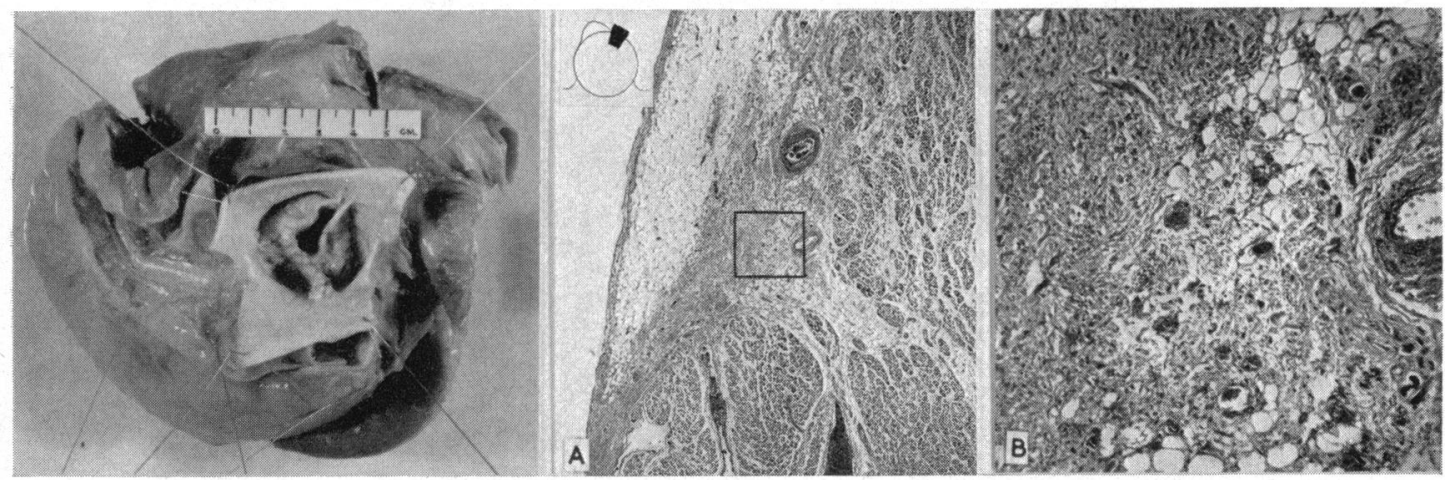

FIG. 9.- Severely damaged node in heart with calcific aortic stenosis but no arrhythmia. From a man of 61 who had also thrombosis in the abdominal aorta and cardiac jaundice. (A) General view of surviving node mainly to the left of the two arteries. Verhoeff-van Gieson. $\times 9$. (B) Detail of area inside rectangle of (A), showing severe depletion of node muscle, fatty replacement, and scattered hæmorrhage. $\times 58$.

Fig. 8 shows a clear example of elastosis of the node. The heart shows extensive recent myocardial infarction which is mainly posterior and basal, as indicated by the arrows. The patient was a woman of 68 who had paroxysmal atrial fibrillation. Fig. 8A shows how the elastic tissue has rendered the node very distinct, and there are three arteries visible. Fig. 8B shows the widespread distribution of this elastic tissue with loss of nodal muscle. 
The question might be asked at this stage. Is it possible to tell whether there was an arrhythmia in life from the appearance of the node? In 14 of the 15 cases with obviously damaged nodes, the forecast I made was correct, but in the fifteenth, which occurred late in the series, I was wrong. It was from a man of 61 with calcific aortic valve stenosis, thrombosis of the abdominal aorta, and cardiac jaundice, and there was no arrhythmia. Fig. 9 shows the aortic valve stenosis, and the severely damaged node: in (A) there are two node arteries, with node mainly to the left of them, and (B) shows great depletion of node muscle, with fatty replacement and scattered hæmorrhage. The right atrium in this heart was almost normal, but I must confess to my astonishment that this man had not had an arrhythmia. It is possible that there was still sufficient functioning nodal tissue; it is also possible that his heart was about to fibrillate when he died. However, this case does emphasize the importance of examining the whole node area because even when this is done, as in this case, one may misinterpret the node function in life.
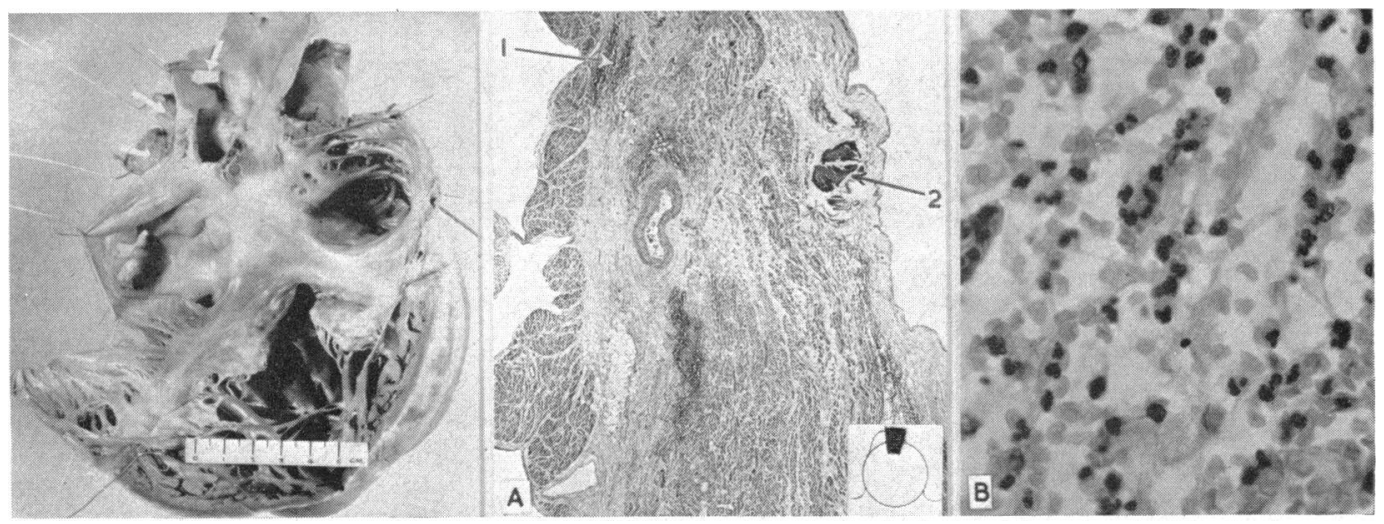

FIG. 10.-Surgical trauma of the node in a heart, with sinus venosus type of atrial septal defect, a tentrance of superior vena cava and anomalous right pulmonary veins (white arrows). From a woman of 46 with paroxysmal fibrillation before operation and evidence of shifting pacemaker during the operation. The heart is shown from the right side. (A) General view of node (already diseased) with dark traumatic hæmorrhagic inflammatory areas above and below the artery. Arrow 2 indicates a surgical stitch in the epicardium. Hæmatoxylin-eosin. $\times 9$. (B) Acute inflammatory reaction in the area indicated by the arrow 1 in (A). $\times 365$.

Surgical Trauma. In the group with severely damaged nodes and arrhythmia, there were two examples of additional surgical trauma. The node is in some danger at heart operations. The atrial incision may divide it; the superior vena caval tourniquet may damage it; it may be crushed by forceps; or it may be involved in suturing.

The first example was found in a woman of 46 with the sinus venosus type of atrial septal defect and anomalous right pulmonary veins (indicated by the white arrows in Fig. 10). Before the operation for repair of the defect, paroxysmal fibrillation was present. During operation, the electrocardiogram showed atrial fibrillation, nodal rhythm, and then coronary sinus rhythm-indicating a shift of the pacemaker. (Similar changes occur in hypothermia in other cases.) However, the node proved to be a very poor one, with added traumatic hæmorrhagic inflammation seen as the dark areas in Fig. 10A above and below the node artery. At the area marked by arrow 1, there was acute inflammatory reaction (Fig. 10B) and a surgical stitch appeared in the epicardium at the point of arrow 2.

The second example of additional surgical trauma was in the node of the heart from a young woman with the ostium secundum type of atrial septal defect. There had been a history of paroxysmal atrial flutter for four years. Surgical repair of the defect was undertaken but she died. The node proved to be small with depleted muscle, and in addition there was an extensive hæmorrhagic necrosis in and near the node, and fibrin on the epicardial surface. 


\section{OTHER FeAtURES}

There was one heart among the 65 in which the node was not located with certainty. It was from a woman of 28 with atrial fibrillation, and was an example of single atrium. The node landmark was not evident, and so far, 22 blocks of tissue from the likely area have failed to show more than a distinct artery, with a few node-like fibres. It is possible that the node was so badly damaged that it is unrecognizable. It is just as likely, however, that the node has not yet been found owing to the absence of its landmark.

In addition to the more severe lesions already described, several other interesting features were noted in the course of the study, and these may be considered under three headings: (1) vascular lesions, (2) hypertrophy, and (3) neoplasms.

(1) Vascular Lesions. The commonest of all node lesions in this series of 65 hearts was focal hamorrhage. Fig. 11A shows focal hæmorrhage in the lower part of the node, adjacent to the atrial



FIG. 11.-(A) Focal hæmorrhage in lower part of node. From a woman aged 60 with normal rhythm. The heart showed rheumatic aortic stenosis. Hæmatoxylin-eosin. $\times 54 . \quad(B$ and $C)$ Localized hypertrophy, mainly medial, of node artery with stenosis of lumen. From a woman of 47 with mitral stenosis, pulmonary hypertension, and atrial fibrillation. (B) General view of node which is large and extends to the bottom of the picture into the atrial myocardium. There is much reduction of muscle with fibro-fatty replacement. (The other strips of tissue showed small arteries). Verhoeff-van Gieson. $\times 9$. (C) Medial hypertrophy, with moderate intimal thickening. $\times 54$.

myocardium. This section was from a woman of 60 with aortic valve stenosis and mitral regurgitation, without any arrhythmia. Apart from the hæmorrhage, the node was within normal limits.

It is possible that focal hæmorrhage and other lesions such as active rheumatism may damage the node temporarily, and this might be associated with a passing arrhythmia. With resolution of the lesion, the node could carry on functioning normally. This process might occur several times until the node is so damaged that a permanent arrhythmia is established.

Arterial lesions in the node itself were hardly seen at all in this study. There was one example of localized hypertrophy of the artery in the node in the heart of a woman of 47 with mitral stenosis, tricuspid regurgitation, and pulmonary hypertension. There had been atrial fibrillation. In one of the pacemaker blocks only, the artery was stenosed and its media grossly thickened (Fig. 11, B and $\mathrm{C}$ ). The node itself was severely damaged but $I$ think this was from rheumatism rather than from ischæmia.

Atheroma of the artery in the node was mild and uncommon. Although the artery in the node rarely showed abnormality, this is not to say that the arteries in their course to the node do not 
suffer the same lesions as those of the rest of the coronary arterial system, and this is probably the cause of node damage in the cases of cardiac infarction.

(2) Hypertrophy. There was one outstanding example of hypertrophy of the node-indeed it was the largest in the series. It was found in the heart of a man who suffered from Refsum's syndrome-a rare form of familial polyneuritis with night blindness, cerebellar ataxia, and other nervous manifestations. The heart showed gross hypertrophy of the left ventricle, and the myocardium throughout showed non-specific degenerative changes (Gordon and Hudson, 1959). The node extended from the medial to the lateral side. Fig. 12A shows it extending just under the endocardium right down the right half of the picture and Fig. 12B shows the abundant normal node muscle with a few strands of dark fibrous tissue. There was no arrhythmia. Fig. 12C is interesting in showing not only that the node is still very large on the medial side, but also that the node artery is cut longitudinally as it ascends in the epicardium at the lower right side of the picture.

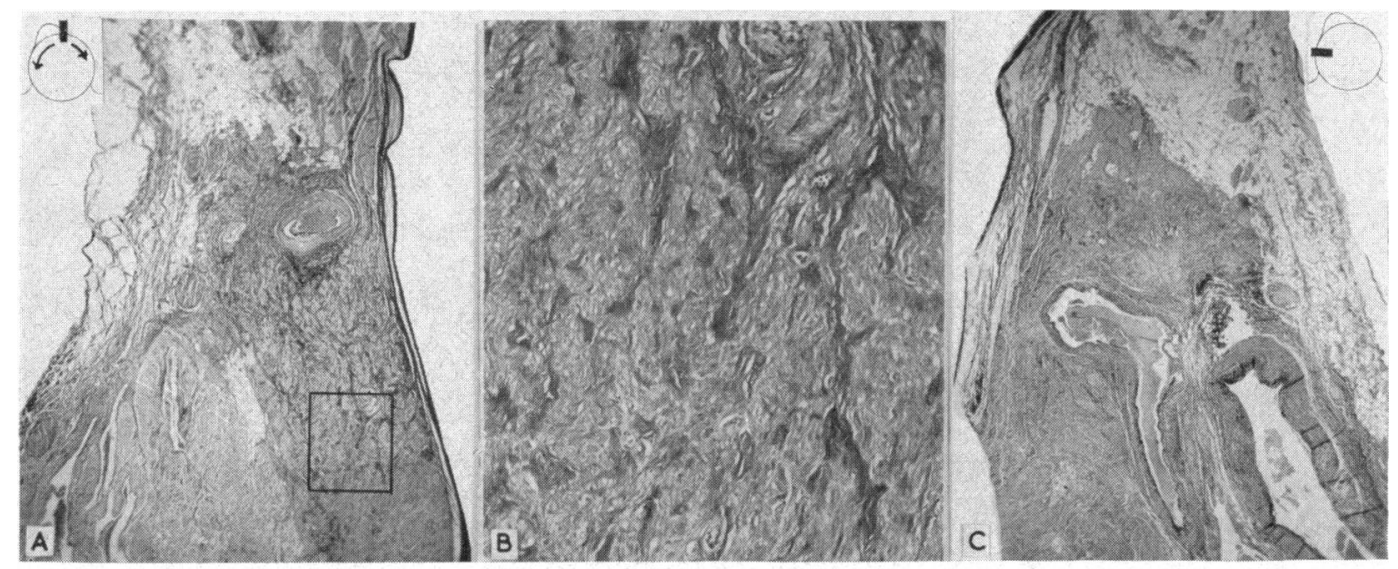

FIG. 12.-Hypertrophy of the node in the heart of a man with Refsum's syndrome. The heart showed massive hypertrophy of the left ventricle, and widespread non-specific degenerative changes in the myocardium. The rhythm was normal. (A) General view of the large node which lies under the endocardium and extends out of the bottom of the picture. The arrows in the ground plan show how the node extended, being quite easily found at the arrow-points. Verhoeff-van Gieson. $\times 9$. (B) Area in rectangle of (A) to show the abundant muscle (pale). $\times 54$. (C) Node still large and clear. Main artery ascending in epicardium from bottom right corner. The artery in the node is shaped like a 7 . Verhoeff-van Gieson. $\times 9$.

Lev (1954) described the changes in the node of the normal heart at various ages. I have not been able to correlate appearances with age very well, possibly because the hearts were abnormal. Increase of fibrous, elastic, and fatty components of the node with advancing age, such as Lev described, has not been noted with any consistency. I have not encountered a true example of node atrophy. Whenever the node has been small, it has been diseased.

(3) Neoplasms. The series included two cases of bronchial carcinoma in which the heart was involved, not only by metastases but by infarction also; and one case of rhabdomyoma. In both the bronchial carcinoma cases, the lymphatics adjacent to the node contained metastases, but the node itself was not invaded. In one of the cases, however, I found metastases in the substance of the main bundle of His. The patient was a man of 68 with carcinoma of the left main bronchus, metastases in the liver and suprarenals, cardiac infarction, and infarction of the brain, spleen, and kidney. In spite of this, there was no arrhythmia and the node showed some fibrosis only.

The heart with rhabdomyoma proved extremely interesting. It came from a baby aged 13 days. There was a massive whitish tumour of the interventricular septum (Fig. 13B), and this was bulging into the cavity of the right ventricle, partly obstructing the tricuspid valve (Fig. 13A); it was also erupting into the left ventricle in three places (Fig. 13C). The upper nodule was obstructing the aortic valve and actually herniating into the right coronary ostium. 
Histologically, the appearances were typical of this tumour (which is probably not a true tumour, but a hamartoma or maldevelopment): these are seen in Fig. 13E, which shows the characteristic sponge-like tissue of vacuolated cells (which some workers have demonstrated to contain glycogen). In the centre is a so-called "spider cell," in which the nuclear components of the cell are connected to the cell membrane by fine thread-like strands. Although Fig. 13E shows little sign of striated muscle, numerous areas nearby showed typical myocardial striation (Fig. 13F).



FIG. 13.-Rhabdomyoma in the heart of a baby 13 days old. (A) Right ventricle, showing bulging of interventricular septum. (B) Main tumour mass in interventricular septum. (C) Left ventricle, showing three pale nodules of tumour. The upper one is obstructing the aortic valve and right coronary ostium. (D) Nodule of tumour (arrowed) immediately below the node. Verhoeff-van Gieson. $\times 19$. (E) General view of the tumour, showing the sponge-like tissue of vacuolated cells with a "spider cell" in the centre. $\times 75$. (F) Myocardial striation of the vacuolated cells. $\times 315 . \quad$ (E) and (F) phosphotungstic acid-hæmatoxylin.

Sections from various parts of this heart showed numerous small masses like the main one and the heart probably contained hundreds. I was fortunate, considering the size of the heart, to secure the section illustrated in Fig. 13D, which shows the node around the artery and, immediately below it, a rhabdomyoma nodule (arrowed).

\section{SUMmaRY AND CONCLUSIONS}

A brief account is given of the historic events leading to the discovery of the sino-auricular node in the mole's heart by Flack and Keith in 1906, and of its identification as the pacemaker of the dog's heart in 1910 by Lewis and his colleagues.

An illustrated account of the anatomy and histology of an average normal human pacemaker follows. Attention is drawn to the summit of the right atrium as the landmark for this structure.

Finally, the various lesions encountered in a study of the node in 65 human hearts are described and illustrated. Besides drawing attention to the surgical risks to the pacemaker, $I$ have emphasized 
the association of a diseased node with established arrhythmia, especially atrial fibrillation, and suggested that temporary arrhythmias may be associated with minor lesions of the node.

Established arrhythmia, especially atrial fibrillation, is commonly associated with disease of the pacemaker. Extended study may show this association to be constant.

This work has been made possible by the patience, skill, and care of my histology technician, Mr. F. Dean, who has shared my enthusiasm in this study. I am much indebted to him and to Miss Nina Lampen, photographer to the Institute of Cardiology, who has given so much willing help with the illustrations.

I am also grateful to my colleagues at the Heart Hospital and Institute of Cardiology for allowing me to study the hearts from patients who had been under their care; to Dr. Leslie Davies for his interpretation of the electrocardiograms of the cases studied; to Dr. R. R. Wilson for sending me the remarkable specimen of rhabdomyoma and to Professor W. Blackwood who sent me the heart from the case of Refsum's syndrome.

\section{REFERENCES}

Argaud, R. (1911). Arch. Mal. Coeur, 4, 638.

Blair, D. M., and Davies, F. (1934-35). J. Anat., 69, 303.

Duckworth, J. W. A. (1952). M.D. Thesis, Univ. of Edin., quoted in A. W. Ham's Histology. Lipincott Co., Philadelphia (1953).

Eyster, J. A. E., and Meek, W. J. (1921). Physiol. Rev., 1, 1.

Glomset, D. J., and Glomset, A. T. A. (1940). Amer. Heart J., 20, 389.

Gordon, N., and Hudson, R. E. B. (1959). Brain, 82, 41.

Keith, A., and Flack, M. (1907). J. Anat. Physiol., 41, 172.

- , (1942). Brit. Heart J., 4, 77.

(1948). Human Embryology and Morphology. 6th ed. Edward Arnold \& Co., London.

Lev, M. (1954). J. Geront., 9, 1.

Lewis, T., Oppenheimer, B. S., and Oppenheimer, A. (1910-11). Heart, 2, 147.

- Meakins, J., and White, P. D. (1914). Phil. Trans. Royal Soc., 205, 375.

Lewis, Sir Thomas (1925). The Mechanism and Graphic Registration of the Heart-beat. 3rd ed., Shaw and Sons, Ltd., London.

Meiklejohn, J. (1914). J. Anat. Physiol., 48, 1.

Oppenheimer, B. S., and Oppenheimer, A. (1912). J. exper. Med., 16, 613.

Puech, P., Esclavissat, M., Sodi-Pallares, D., Cisneros, F. (1954). Amer. Heart J., 47, 174.

Stotler, W. A., and McMahon, R. A. (1947). J. comp. Neurol., 87, 57.

Taussig, H. B. (1931). Bull. Johns Hopk. Hosp., 48, 162. 